\title{
Epicutaneous Sensitization with Protein Antigen Induces Localized Allergic Dermatitis and Hyperresponsiveness to Methacholine after Single Exposure to Aerosolized Antigen in Mice
}

\author{
Jonathan M. Spergel,, ${ }^{\star}$ Emiko Mizoguchi, ${ }^{\ddagger}$ Joanne P. Brewer, ${ }^{\S}$ Thomas R. Martin, ${ }^{\S}$ Atul K. Bhan, ${ }^{\ddagger}$ and Raif S. Geha* \\ *Division of Immunology, Children's Hospital, Harvard Medical School, Boston, Massachusetts 02115; Department of \\ Immunopathology, Pathology Department, Massachusetts General Hospital, Boston, Massachusetts 02114; and ${ }^{\S}$ Division of Pulmonary \\ Medicine, Children's Hospital, Harvard Medical School, Boston, Massachusetts 02115
}

\begin{abstract}
Our understanding of the pathogenesis of atopic dermatitis (AD) and its relationship to asthma remains incomplete. Herein, we describe a murine model of epicutaneous (EC) sensitization to the protein allergen, chicken egg albumin, ovalbumin (OVA), which results in a rise in total and OVAspecific serum IgE and leads to the development of a dermatitis characterized by infiltration of $\mathrm{CD3}^{+} \mathrm{T}$ cells, eosinophils, and neutrophils and by local expression of mRNA for the cytokines IL-4, IL-5, and interferon- $\gamma$. A single exposure of the EC sensitized mice to aerosolized OVA induced eosinophilia in the bronchoalveolar lavage fluid and airway hyperresponsiveness to intravenous methacholine as assessed by measurement of pulmonary dynamic compliance $\left(C_{d y n}\right)$. These results suggest a possible role for EC exposure to antigen in atopic dermatitis and in the development of allergic asthma. (J. Clin. Invest. 1998. 101:1614-1622.) Key words: mice $\cdot$ atopic dermatitis - epicutaneous sensitization • cytokines $\bullet$ asthma

\section{Introduction}

Atopic dermatitis $(\mathrm{AD})^{1}$ is a common chronic pruritic inflammatory skin disease that often begins in infancy and frequently occurs in subjects with a personal or family history of atopic disease. The majority of infants with AD develop asthma and/ or allergic rhinitis later in life (1).
\end{abstract}

Address correspondence to Raif S. Geha, M.D., Enders 8, Division of Immunology, 300 Longwood Avenue, Children's Hospital, Boston, MA 02115. FAX: 617-355-8205; E-mail: Geha@A1.TCH. HARVARD.EDU

Received for publication 3 September 1997 and accepted in revised form 16 February 1998.

1. Abbreviations used in this paper: $\mathrm{AD}$, atopic dermatitis; $\mathrm{BAL}$, bronchoalveolar lavage; $\mathrm{C}_{\mathrm{dyn}}$, dynamic compliance; $\mathrm{EC}$, epicutaneous; $\mathrm{G}_{\mathrm{L}}$, pulmonary conductance; $\mathrm{H} \& \mathrm{E}$, hematoxylin and eosin; HPF, high power fields; IP, intraperitoneal; Mch, methacholine; OVA, ovalbumin.

J. Clin. Invest.

(C) The American Society for Clinical Investigation, Inc. 0021-9738/98/04/1614/09 \$2.00

Volume 101, Number 8, April 1998, 1614-1622

http://www.jci.org
Examination of affected skin lesions in AD suggests that $\mathrm{T}$ cells play an important role in the pathogenesis of the disease. Immunohistologic analysis reveals a mononuclear cell infiltrate, predominantly in the dermis, consisting of activated memory CD4 ${ }^{+} \mathrm{T}$ cells bearing HLA-DR ${ }^{+}$and $\mathrm{CD} 45 \mathrm{RO}^{+}$and of macrophages (2). In acute lesions of $\mathrm{AD}$, there is a significant increase in the number of cells expressing IL-4 and IL-5 mRNA and protein, suggesting preferential accumulation of Th2 cells. In the chronic skin lesions of AD, cells containing IFN- $\gamma$ mRNA and protein predominate over those containing IL-4 and IL-5 (3). Vascular endothelial cells in AD skin lesions have increased expression of the adhesion molecules E-selectin, VCAM-1, and ICAM-1 $(4,5)$. Products of eosinophils, which express VLA-4, the counterligand for VCAM-1, are readily detectable in the skin lesions of AD (6).

Several observations suggest that allergens play an important role in AD. Approximately $80 \%$ of patients with $\mathrm{AD}$ have elevated levels of serum $\operatorname{IgE}$ and evidence of $\operatorname{IgE}$ antibody to a variety of food and inhaled allergens (7). Well-controlled studies have demonstrated that food allergens can exacerbate skin rashes in a subset of patients with $\mathrm{AD}(8)$. A role for inhaled allergens in $\mathrm{AD}$ is suggested by the observation that pruritus and eczematoid skin lesions develop in patients with AD after inhalation challenge with aeroallergens (9). Epicutaneous (EC) application of a number of inhalant allergens to normal skin sites elicits a positive reaction (10) and patch testing of abraded skin with mite extract results in an eczematous rash in patients with AD (11). Several studies have shown that avoidance of aeroallergens that elicit eczematous reactions in patch tests or that elicit skin immediate hypersensitivity reactions results in clinical improvement $(12,13)$. Finally, T cells isolated from AD skin lesions have been shown to proliferate and secrete IL-4 in response to dust mite antigen (14). These observations are consistent with the hypothesis that EC exposure to allergens may play a role in AD.

The notion that EC sensitization leads to a Th2 type immune response is supported by the results of two recent studies in which application of the antigen ovalbumin (OVA) to mouse skin resulted in the induction of antigen-specific IgE $(15,16)$. In one of these studies, draining lymph node $\mathrm{T}$ cells were shown to secrete IL-4, but not IFN- $\gamma$, in response to in vitro stimulation with OVA (16). Neither of these studies have investigated the skin.

We describe here the development of a cellular infiltrate rich in T cells and eosinophils and the presence of IL-4, IL-5, and IFN- $\gamma$ mRNA in the skin of mice EC sensitized with OVA. In addition to antigen-specific IgE, these mice developed airway hyperresponsiveness to intravenous methacholine (Mch) after a subsequent single inhalation challenge with OVA. 


\section{Methods}

Mice sensitization. 4-6-wk-old female BALB/c mice were purchased from Taconic Laboratories (Germantown, NY) and kept in a pathogen-free environment. All procedures performed on the mice were approved by the Animal Care and Use Committee of the Children's Hospital, Boston.

EC sensitization of mice was performed as described by Wang et al. (16). Briefly, mice were anesthetized with methoxyflurane (Metofane; Mallinckrodt Veterinary, Mundelein, IL), then shaved with an electric razor. $100 \mu \mathrm{g}$ of OVA (grade V; Sigma Chemical Co., St. Louis, MO) in $100 \mu \mathrm{l}$ of normal saline or placebo (100 $\mu \mathrm{l}$ of normal saline) was placed on a $1 \times 1 \mathrm{~cm}$ patch of sterile gauze, which was secured to the skin with a transparent bioocclusive dressing (Johnson and Johnson Medical Inc., Arlington, TX). The patch was placed for a 1-wk period and then removed. 2 wk later, an identical patch was reapplied to the same skin site. Each mouse had a total of three 1-wk exposures to the patch separated from each other by 2-wk intervals (Fig. 1). Inspection confirmed that the patch remained in place at the end of each sensitization period. Intraperitoneal (IP) sensitization of another group of mice was performed with OVA $(100 \mu \mathrm{g})$-alum and boosted 2 wk later with the same dose of OVA in alum.

Antibodies. Rat and hamster mAbs were used for immunohistochemical analysis and were directed against mouse CD3€ (1452C11), CD4 (H129.19), CD8 $\alpha$ (53-6.7), TCR- $\gamma$ (GL3), CD45 (30F11.1), I-A ${ }^{\text {b,d,p,q }}$ (25-9-7), CD54-ICAM-1 (3E2), CD106-VCAM (429/MVCAM.A), and CD14 (rmC5-3). mAbs used in ELISA were biotin-conjugated rat antibodies to mouse IgG1 (clone G1-7.3), IgG2a (clone R19-15), IgG2b (clone R12-3), IgG3 (clone R2-38), and IgE (clone R35-92). IgE mAb clone R35-72 and clone R35-92 were used for detection of total IgE. All antibodies were purchased from PharMingen (San Diego, CA).

ELISA. Mice were bled and sera were collected $1 \mathrm{~d}$ after the end of the series of three EC sensitizations (Fig. 1). The standard PharMingen protocol was used to quantify the total amount of IgE in serum. Rat anti-mouse IgE mAb clone R35-72 was used for coating the plates and rat anti-mouse IgE mAb clone R35-92 was used for detection.

IgG1, IgG2a, IgG2b, and IgG3 OVA-specific antibodies were measured as described by Renz et al. (17). In brief, 96-well microtiter plates were coated with $50 \mu \mathrm{g} / \mathrm{ml}$ of OVA in $0.1 \mathrm{M} \mathrm{NaHCO}_{3}$ at $4{ }^{\circ} \mathrm{C}$ overnight. The plates were washed with PBS-Tween 20 (0.05\%), then blocked with $3 \%$ PBS-BSA for $2 \mathrm{~h}$ at $20^{\circ} \mathrm{C} .100 \mu \mathrm{l}$ of serial dilutions of sera in $1 \% \mathrm{BSA} / \mathrm{PBS}$ was incubated overnight at $4^{\circ} \mathrm{C}$. After washing with PBS-Tween 20, biotin-labeled anti-mouse isotype-specific antibody $(1.5 \mu \mathrm{g} / \mathrm{ml})$ was added for $2 \mathrm{~h}$. After washing with PBSTween, streptavidin-horseradish peroxidase (Amersham Life Sciences, Arlington Heights, IL), diluted 1:500 in 1\% BSA/PBS, was incubated for $30 \mathrm{~min}$ at room temperature. The plates were then washed with PBS-Tween, $o$-phenylenediamine substrate (Sigma Chemical Co.) was added, and absorption at $492 \mathrm{~nm}$ was read.
A different method was used to determine IgE OVA-specific antibody, since IgE may represent a small amount of the total antibody response to specific antigen. Plates were coated with rat anti-mouse IgE (clone R35-72; PharMingen) in $0.1 \mathrm{M} \mathrm{NaHCO}_{3}$ overnight at $4^{\circ} \mathrm{C}$. The plates were blocked with $3 \%$ BSA-PBS for $2 \mathrm{~h}$, then serial dilutions of sera were incubated overnight at $4^{\circ} \mathrm{C}$. After washing with PBS-Tween, biotin-labeled OVA was added and incubated for $2 \mathrm{~h}$. Streptavidin-horseradish peroxidase and $o$-phenylenediamine were added and absorption was read as above.

The antibody titers of the sample were calculated by comparison with internal standards $(16,17)$. Anti-OVA IgE and IgG serum standards were obtained by pooling sera from five mice sensitized with OVA via the IP route as described above. The standard curve was constructed by a linear regression analysis of the absorbances versus serial dilutions of the positive reference sera. Results are expressed as ELISA titers relative to an internal isotype standard run in each assay $(16,17)$. The standard was assigned to IgG1-50, IgG2a-40, IgG2b-500, IgG3-3, and IgE-20 arbitrary units.

Histological analysis. For histological examination, specimens were obtained from patched as well as adjacent nonpatched areas on the skin $24 \mathrm{~h}$ after the patch from the third sensitization was removed. Specimens were fixed in $10 \%$ buffered formalin and embedded in paraffin. Multiple 4- $\mu \mathrm{m}$ sections were stained with hematoxylin and eosin $(\mathrm{H} \& \mathrm{E})$. Individual inflammatory cell types were counted in 10-20 high power fields (HPF); and expressed as cells/HPF with mean and SEM calculated.

Immunohistological analysis. Skin sections were embedded in Tissue-Tek O.C.T. compound (Miles Inc., Elkhart, IN) on dry ice. Sections of $4 \mu \mathrm{m}$ were prepared and stored at $-80^{\circ} \mathrm{C}$. Sections were stained by an avidin-biotin complex method as described previously (18). Briefly, the sections were fixed in cold acetone for $7 \mathrm{~min}$, airdried, and incubated with purified rat or hamster anti-mouse mAbs. Specimens were then incubated with biotinylated rabbit anti-rat Ig (Vector Laboratories, Burlingame, CA) or biotinylated goat antihamster Ig (Vector Laboratories) followed by avidin-biotinylated peroxidase complex (Dako, Carpinteria, CA). Endogenous peroxidase activity was blocked with a 30-min incubation with $0.3 \%$ hydrogen peroxide in PBS. Endogenous biotin was blocked by sequential incubations with avidin (Vector Laboratories) and biotin (Sigma Chemical Co.). The tissue sections were stained by incubation in a solution of 3-amino-9-etylcarbazole (Aldrich Chemical Co., Milwaukee, WI) and postfixed with $2 \%$ paraformaldehyde and mounted with Glycergel (Dako).

$R N A$ preparation. Skin biopsies were obtained $24 \mathrm{~h}$ after the third patch was removed and immediately frozen in dry ice. To extract the RNA, the samples were homogenized in Trizol (GIBCO BRL, Gaithersburg, MD) using a Polytron RT-3000. RNA quantity was determined by measuring optical density at $260 \mathrm{~nm}$.

cDNA synthesis. cDNA was synthesized from $10 \mu \mathrm{g}$ of total RNA in a $50-\mu l$ reaction mix which contained $0.5 \mu \mathrm{g}$ of oligo(dT $)_{12-18}$ (Pharmacia Biotech Inc., Piscataway, NJ), 50 mM Tris-HCl, $\mathrm{pH} 8.3$,

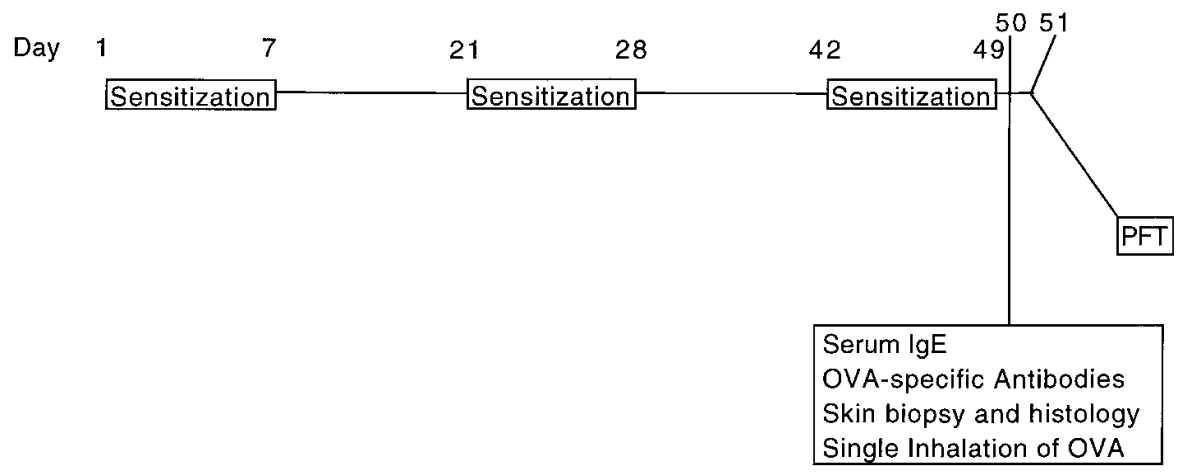

Figure 1. Sensitization protocol. Mice were sensitized with OVA $(100 \mu \mathrm{g})$ or saline applied in $100 \mu \mathrm{l}$ to a sterile patch. The patch was placed for a 1-wk period, then removed. 2 wk later, an identical patch was reapplied to the same skin site. Each mouse had a total of three 1-wk exposures to patch separated from each other by 2 -wk intervals. All experiments were done at the end of the third sensitization. PFT-whole body plethysmograph measured as $\mathrm{C}_{\mathrm{dyn}}$ and $\mathrm{G}_{\mathrm{L}}$. 
Table I. Sequences of the Oligonucleotides Used in the RT-PCR Reactions

\begin{tabular}{llc}
\hline \multicolumn{1}{c}{ Cytokine } & Sense primer $\left(5^{\prime}-3^{\prime}\right)$ & Antisense primer $\left(5^{\prime}-3^{\prime}\right)$ \\
\hline IL-1 $\alpha$ & CAGTTCTGCCATTGACCATC & TCTCACTGAAACTCAGCCGT \\
IL-2 & GACACTTGTGCTCCTTGTCA & TCAATTCTGTGGCCTGCTTG \\
IL-4 cDNA & TCGGCATTTTGAACGAGGTC & GAAAAGCCCGAAAGAGTCTC \\
IL-4 pMUS & TCGACATTTTGAACGAGGTC \\
IL-5 & TCACCGAGCTCTGTTGACAA & GAAAAGCCCGAAAGAGTCTC \\
IFN- $\gamma$ & GCTCTGAGACAATGAACGCT & CCACACTTCTCTTTTGGCG \\
TNF- $\alpha$ & TCTCATCAGTTCTATGGCCC & AAAGAGATAATCTGGCTCTGC \\
$\beta 2-$ microglobulin & TGACCGGCTTGTATGCTATC & GGGAGTAGACAAGGTACAAC \\
& & CAGTGTGAGCCAGGATATAG
\end{tabular}

The 5' nucleotide sequence of IL-4 in pMUS has a single base substitution, hence the single base difference in the $5^{\prime}-3^{\prime}$ primers used to hybridize to cellular IL-4 cDNA and to IL-4 sequences in pMUS.

$75 \mathrm{mM} \mathrm{KCl}, 3 \mathrm{mM} \mathrm{MgCl}$, $0.5 \mathrm{mM}$ dNTP, $1 \mathrm{U}$ of RNasin (Promega, Madison, WI), and 1 U Superscript II (GIBCO BRL). After incubation for $90 \mathrm{~min}$ at $37^{\circ} \mathrm{C}$, the reaction was stopped by incubating at $92^{\circ} \mathrm{C}$ for $30 \mathrm{~s}$, then immediately cooling on ice.

$P C R$ amplification of reverse-transcribed $c D N A$. The primers used to amplify cDNA for $\beta 2$-microglobulin, IL-1, IL-2, IL-4, IL-5, IFN- $\gamma$, and TNF- $\alpha$, were based on the sequences published by the European Cytokine Network (19) and are shown in Table I. DNA amplification was carried out in Boehringer Mannheim-supplied buffer supplemented with $50 \mu \mathrm{m}$ dNTPs, $25 \mu \mathrm{M}$ of specific $5^{\prime}$ and $3^{\prime}$ primers, and $1 \mathrm{U}$ of Taq polymerase (Boehringer Mannheim, Indianapolis, IN). The mixture was overlaid with $50 \mu \mathrm{l}$ of mineral oil and amplified in sequential cycles at $92^{\circ} \mathrm{C}$ for $30 \mathrm{~s}, 56^{\circ} \mathrm{C}$ for $30 \mathrm{~s}$, and $72^{\circ} \mathrm{C}$ for $45 \mathrm{~s}$ in an Ericomp DeltaCycler II for 35 cycles.

Quantification of mRNA was done as described previously by Bouaboula (20). Briefly, a fixed amount of reversed-transcribed cellular mRNA was coamplified in the presence of 10 -fold serial dilutions (100 pg to $1 \mathrm{fg}$ ) of a multispecific internal plasmid control pMUS that contains nucleotide sequences from multiple cytokines (19). The plasmid is engineered such that DNA amplification by PCR using the appropriate primers results in a 300-bp product for each cytokine. This would result in a 73-99 bp, a size difference between the PCR products amplified from pMUS and those amplified from cDNA reverse transcribed from cellular mRNA. Plasmid and cDNA compete for binding to the specific primers, allowing relative quantification (20). Samples were run on $1.6 \%$ agarose gel in the presence of ethidium bromide. After gel separation, equal ethidium bromide band intensities of both fragments were used to determine the amount of cellular cDNA. The results were expressed as a ratio of cytokine cDNA to cDNA of the constitutively expressed $\beta 2$ microglobulin gene.

Bronchoalveolar lavage (BAL). $0.8 \mathrm{ml}$ of PBS with $10 \% \mathrm{FCS}$ and $1 \mathrm{mM}$ EDTA was infused via the trachea to lung and was retrieved. BAL leukocytes and eosinophils were counted under HPF $(\times 400)$ after staining with Diff-Quick stain (Baxter Healthcare Corp., Deerfield, IL).

Pulmonary function and cholinergic responsiveness measurements. Pulmonary conductance $\left(\mathrm{G}_{\mathrm{L}}\right)$ and pulmonary dynamic compliance $\left(C_{d y n}\right)$ changes were measured in response to Mch, administered via a jugular venous catheter to anesthetized and ventilated mice in a whole-body plethysmograph as described previously (21). The output signals from $8-10$ consecutive breaths were analyzed using a computerized cross-correlation method (22). The minimal $G_{L}$ and $\mathrm{C}_{\mathrm{dyn}}$ values within $1 \mathrm{~min}$ after each of the geometrically increasing doses of Mch were expressed as a percentage of the baseline values before that dose.

Statistical analysis. Two-way functional ANOVA was performed to assess group and dilution effects and their interactions. A significant $\mathrm{F}$ test for the interaction term would indicate slope differences among the groups. Groups were then compared at each of the dilutions using one-way ANOVA followed by multiple $t$ test with a conservative Bonferroni correction. A two-tailed $P<0.05$ was considered statistically significant for all comparisons.

\section{Results}

EC sensitization with OVA induces elevated serum IgE levels and $O V A$-specific IgE antibodies. To examine the role of EC sensitization with protein antigen in IgE-mediated allergic sensitization, we sensitized BALB/c mice by applying an occlusive patch $(1 \times 1 \mathrm{~cm})$ impregnated with $100 \mu \mathrm{g}$ of OVA, or with saline, to the shaved skin of the back (Fig. 1). As a positive control, mice were injected IP with $100 \mu \mathrm{g}$ of OVA in alum. Fig. $2 \mathrm{~A}$ shows that EC sensitization with OVA resulted in a sixfold increase in total serum $\mathrm{IgE}$ over controls exposed to saline impregnated patches (mean \pm SEM, 3,741 $\pm 1,022$ vs. $658 \pm 309$ ng/ml, $n=10$ each, $P<0.01, t$ test). As anticipated (15), total serum IgE levels did not significantly increase after IP immunization with OVA $(905 \pm 375 \mathrm{ng} / \mathrm{ml}, P>0.05)$.

OVA-specific antibodies of the IgE isotype and of all four isotypes of $\mathrm{IgG}$ were detected in the EC sensitized and in the IP immunized mice, but not in the control mice sham-sensitized with saline. Fig. 2, $B$ and $C$, shows that EC sensitization resulted in significantly higher serum levels of OVA-specific $\mathrm{IgE}$ and IgG1 antibodies than did IP immunization $(P<0.05)$. EC immunization resulted in lower serum levels of OVA-specific $\mathrm{IgG} 2 \mathrm{a}$ and $\mathrm{IgG} 2 \mathrm{~b}$ antibodies compared with IP sensitization (Fig. 2, $D$ and $E$ ). However, the difference was significant for only $\operatorname{IgG} 2 \mathrm{~b}(P<0.05)$. The IgG3 OVA-specific response was weak and did not significantly differ between EC and IP sensitized mice.

EC sensitization leads to local inflammation in the skin. To determine if EC sensitization with protein antigen leads to local inflammation, we performed routine $\mathrm{H} \& \mathrm{E}$ and immunohistochemical analyses of the patched skin. Biopsies from OVA sensitized and saline sensitized mice were taken $1 \mathrm{~d}$ after the completion of a third series of sensitization. There were thickening and inflammation in the dermis and epidermis at the site of EC sensitization with OVA, but not with saline (Fig. 3 , top). Biopsies of skin sites not exposed to antigen were completely normal in OVA sensitized mice (data not shown).

The epidermis of OVA sensitized skin sites exhibited predominance of the stratum granulosum, focal acanthosis, and focal collections of neutrophils with mild spongiosis $(S)$ with 
A)

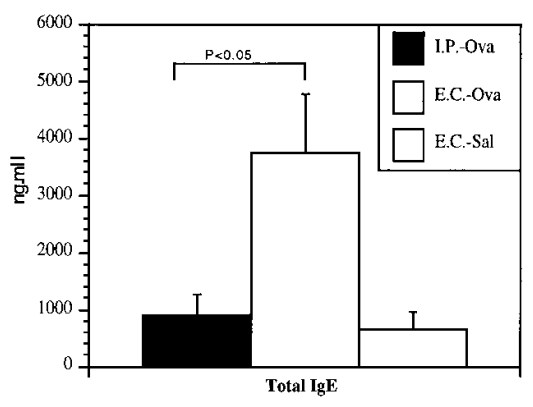

C)

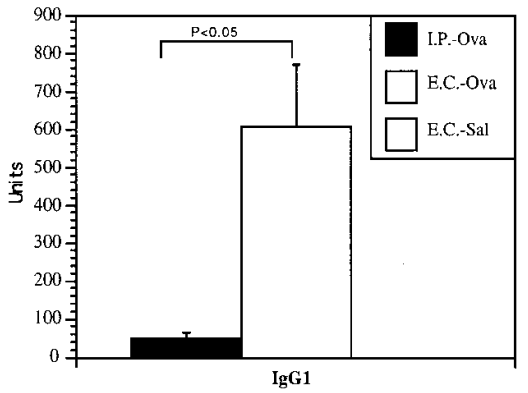

E)

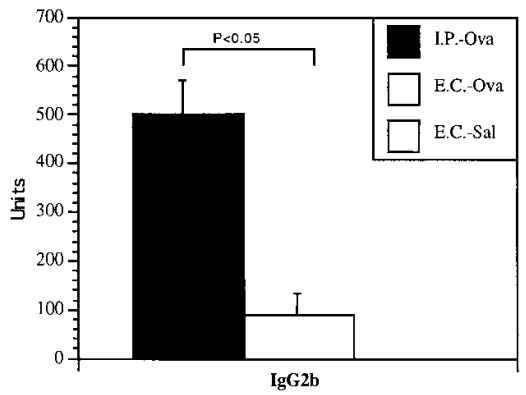

B)

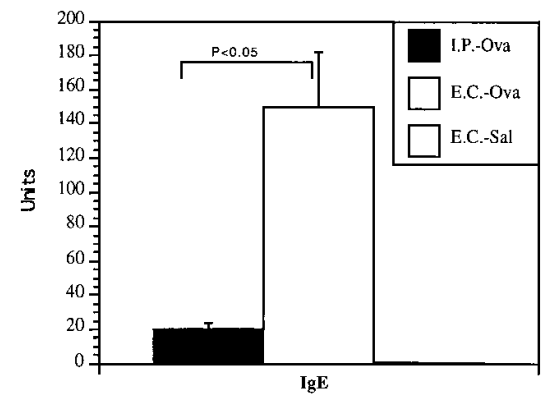

D)

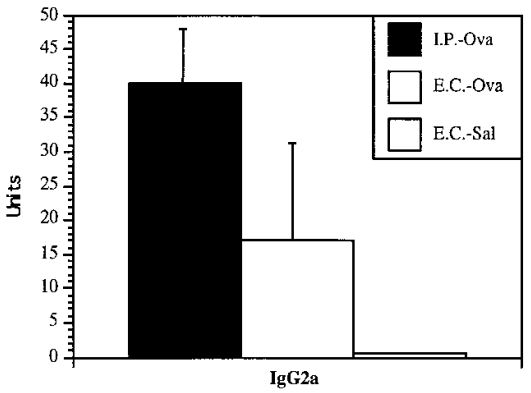

F)

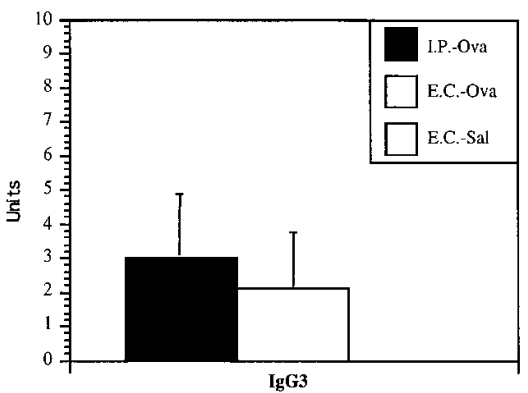

Figure 2. Total $\operatorname{IgE}$ and antigen-specific antibody response in mice sensitized with OVA or saline by the EC route $(n=10$ for each) or by OVA via the IP route $(n=5)$. $(A)$ Total serum IgE. $(B-F)$ Specific OVAspecific antibodies as determined by ELISA. Units for IP sensitized mice are set to 50 for IgG1, 500 for IgG2a, 40 for IgG2b, 3 for IgG3, and 20 for IgE. The columns and error bar represent the mean $\pm \mathrm{SE}$. rare apoptotic cells (Fig. 3, bottom). The epidermal layer was approximately three to five cell layers thick in OVA sensitized sites compared with two to three cell layers thick in saline sensitized sites (Fig. 3) and in unsensitized sites (data not shown). The dermal layer of OVA sensitized, but not of saline sensitized, skin sites was infiltrated with neutrophils, lymphocytes, mast cells, and eosinophils (Fig. 3, bottom). In some areas, the infiltrate penetrated into the subcutaneous fat and muscle layers (data not shown).

We quantified the cellular infiltrate in the epidermis and dermis together by examining $20 \mathrm{HPF}$ and calculating the mean $( \pm \mathrm{SE})$ number of infiltrating cells. Table II shows that OVA sensitized skin sites exhibited a significant increase in the numbers of neutrophils, mononuclear cells, eosinophils, and cells that contained metachromatic granules which probably represent mast cells.

To further characterize the cellular infiltrate in the skin, we performed immunohistochemical analysis on the skin biopsies. OVA sensitized skin showed a significant increase in CD $45^{+}$ cells compared with saline sensitized skin, particularly in the deep dermal layer (Fig. 4). Further identification of the infiltrating cells using a panel of mAbs showed that there was a sig- nificant increase in cells expressing the T cell marker CD3 and in cells expressing CD4 (Fig. 4). Very few $\mathrm{CD}^{+}$cells were identified (Fig. 4). Few TCR $\gamma \delta+$ cells were identified in the epidermal layer. There was increased expression of the adhesion molecule ICAM-1, especially in the vessels and infiltrating cells (Fig. 4) and of VCAM-1 (data not shown).

Cytokine expression in the skin. Induction of high levels of serum IgE and of OVA-specific IgE and the presence of large

Table II. Quantification of the Cellular Infiltrate of the OVA and Saline Sensitized Skin Sites in $H \&$ E Sections

\begin{tabular}{lccc}
\hline \multicolumn{1}{c}{ Cells } & Saline sensitized* & OVA sensitized* & $P$ value \\
\hline Neutrophils & $1.7 \pm 1.51$ & $13.6 \pm 6.2$ & 0.001 \\
Eosinophils & $0.95 \pm 0.14$ & $7.1 \pm 0.77$ & 0.001 \\
Mononuclear cells & $1.2 \pm 0.13$ & $6.4 \pm 0.55$ & 0.001 \\
Mast cells & $2.2 \pm 0.2$ & $7.6 \pm 0.6$ & 0.001 \\
& & & \\
\hline
\end{tabular}

* Mean values are cells per HPF ( \pm SEM) from 20 HPFs. Biopsies were taken $24 \mathrm{~h}$ after the patch from third sensitization was removed. 

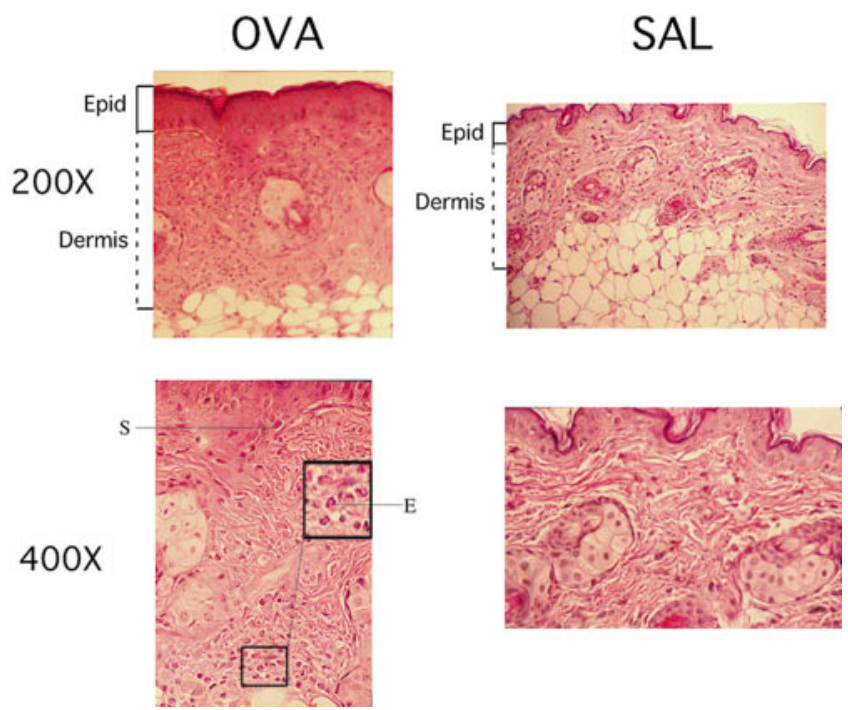

Figure 3. Histological features of OVA and saline sensitized skin sites in BALB/c mice. Skin sections were stained with $\mathrm{H} \& \mathrm{E}$ and examined at $\times 200$ and $\times 400$. There is marked hyperplasia of the epidermis, a dermal infiltrate, and mild spongiosis $(S)$. The cellular infiltrate consists of neutrophils, eosinophils, and lymphocytes. Further magnification of the thin black-bordered box in the inset region (bold black-bordered box) shows the presence of the multiple eosinophils $(E)$.

numbers of eosinophils in the skin suggested that EC sensitization induced a predominant $\mathrm{Th} 2$ response. To test this hypothesis, we examined the presence of mRNA for cytokines in skin sites sensitized with OVA. We used semiquantitative RTPCR, because Northern blot analysis was not sensitive enough to detect cytokine mRNA in the skin biopsies. Fig. $5 \mathrm{~A}$ shows the results of a representative experiment. For each of the cytokines examined, band A represents the PCR amplicon from the indicated amounts $(100,10$, and $1 \mathrm{fg})$ of DNA of the stan- dard plasmid, pMUS, and band B represents the PCR amplicon from the RT cDNA product of $10 \mu \mathrm{g}$ of total RNA. The results show that the constitutively expressed $\beta 2$ microglobulin was expressed to an equivalent extent in OVA and in saline sensitized skin sites. The cytokines IL-2, IL-4, IL-5, and IFN- $\gamma$ were minimally expressed in saline sensitized skin. Expression of IL-4, IL-5, and IFN- $\gamma$, but not of IL-2, was increased after sensitization with OVA. IL-1 was constitutively expressed at a high level in the skin and its expression did not increase further with OVA sensitization in our assay. TNF- $\alpha$ expression was not detectable in either control or OVA sensitized skin (data not shown).

Fig. $5 B$ shows the pooled results of semiquantitative RTPCR on 10 skin biopsies derived from three different experiments with each run in duplicate. The results are expressed as mean \pm SE femtograms of cytokine $m R N A$ per picogram of $\beta 2$ microglobulin. After EC sensitization with OVA, IL-4, IL-5, and IFN- $\gamma$ mRNA expression significantly increased over baseline by 8-, 10-, and 5-fold, respectively. In contrast, there was no increase in IL-2 gene expression. IL-1 mRNA expression was high at baseline (40 fg/pg of $\beta 2$ microglobulin) and did not increase further with OVA sensitization, whereas TNF- $\alpha$ expression was undetectable throughout. These results indicate that EC sensitization with OVA results in the local expression of the Th 2 cytokines IL-4 and IL-5 as well as of IFN- $\gamma$.

EC sensitization by OVA leads to antigen-specific airway sensitization. Accumulation of eosinophils in the BAL fluid after allergen challenge by inhalation is a hallmark of airway sensitization to allergen (23). We challenged EC sensitized mice with a single exposure to inhaled OVA, and $24 \mathrm{~h}$ later we examined BAL fluid for the presence of cells. Fig. $6 \mathrm{~A}$ shows that mice sensitized with OVA had a significant increase in the total number of cells in BAL fluid compared with saline sensitized mice (OVA 3,680 \pm 426 cells/ml, versus saline 2,374 \pm 230 cells $/ \mathrm{ml}, P<0.05)$. More importantly, after challenge with inhaled OVA, there was a significant increase in the number of eosinophils in the BAL fluid of OVA sensitized mice compared with saline sensitized mice (OVA sensitized: 609 144 cells/ml, saline sensitized: $69 \pm 27$ cells $/ \mathrm{ml}, P<0.01)$. OVA sen-

\section{OVA}

\section{$\mathrm{CD} 45$}

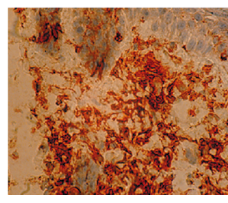

CD3

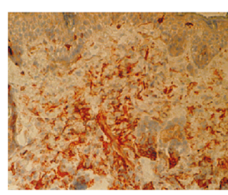

CD4

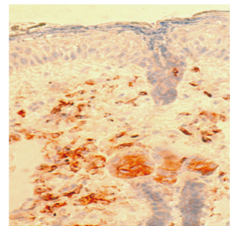

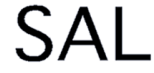
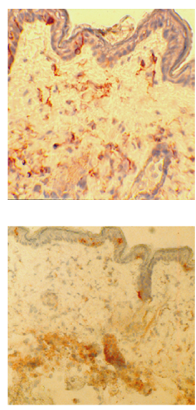

$\gamma \delta$

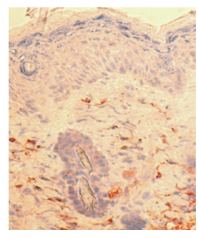

OVA
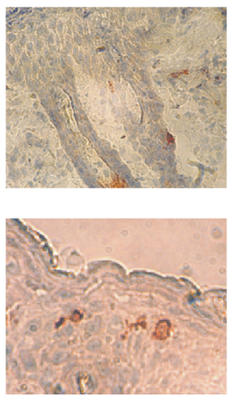

ICAM-1

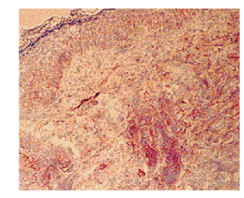

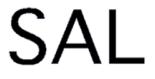
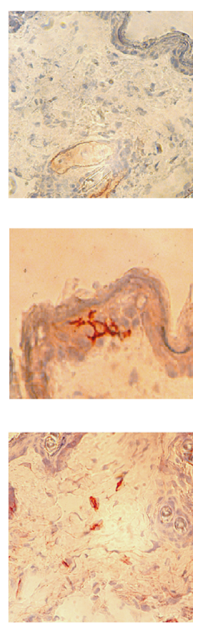

Figure 4. Immunohistochemical staining in the patched areas of the OVA and saline-EC sensitized mice. OVA sensitized mice have an increase in the number of CD45+, CD3+, CD4+, $\gamma \delta+$ cells. Positive cells stain brown. There is also a concomitant increase in the expression of ICAM-1 molecules. Very few CD8+ cells were detected in the biopsies. 
A

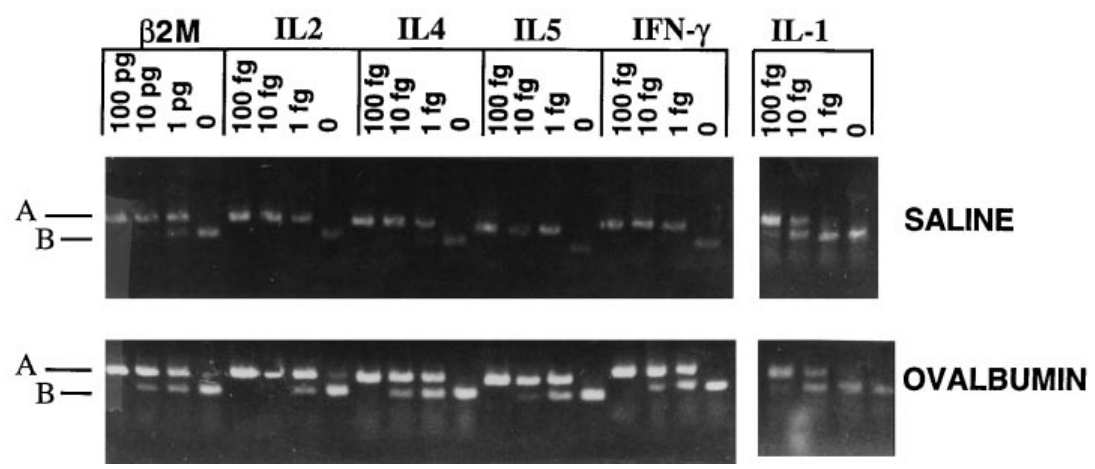

B

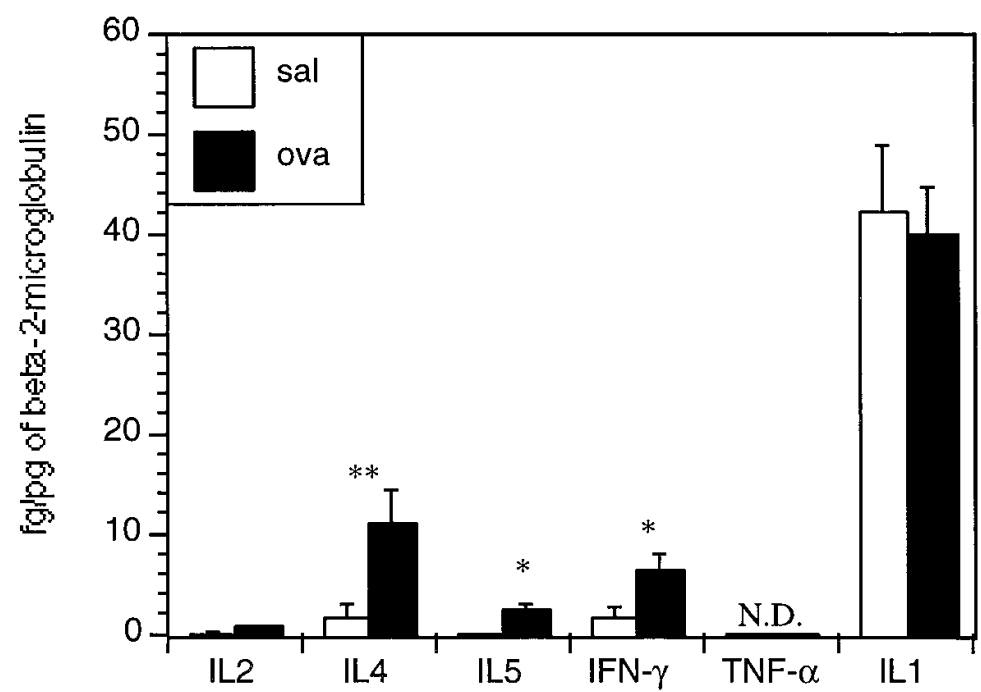

Figure 5. RT-PCR analysis of IL-1, IL-2, IL-4, IL-5, IFN- $\gamma$, and $\beta 2$-microglobulin levels in the skin biopsies from skin sites of BALB/c mice sensitized with OVA or saline. $(A)$ Results of a representative experiment from a pair of mice sensitized with OVA or saline. pMUS plasmid and cDNA were coamplified by Taq polymerase generating 300-bp PCR fragments from the pMUS plasmid (level $A$ ), and 201-271-bp fragments from cytokine cDNAs (level $B$ ). The samples were run on $1.6 \%$ agarose gel and stained with ethidium bromide. $(B)$ Pooled results of experiments using 10 OVA sensitized mice and 10 saline sensitized controls in duplicate. Bars represent mean \pm SE. N.D. $=$ not detected; $* * P=0.01, * P=0.05$.

sitized mice did not develop eosinophilia in BAL fluid after exposure to inhaled saline ( $102 \pm 40$ cells $/ \mathrm{ml} ; P>0.05)$, demonstrating that EC sensitization per se does not result in BAL eosinophilia.

To determine if EC sensitization can prime mice to develop airway hyperresponsiveness, we examined whether inhalation of a single dose of OVA elicits hyperresponsiveness to Mch in EC sensitized mice. $24 \mathrm{~h}$ after exposure to a single dose of inhaled OVA, $G_{L}$ and pulmonary $C_{\text {dyn }}$ responses to graded doses of intravenous Mch were measured plethysmographically in sedated, ventilated mice. The baseline values of $\mathrm{C}_{\mathrm{dyn}}$ and $\mathrm{G}_{\mathrm{L}}$ before the challenge with Mch as well as the response to Mch after inhalation of saline did not differ between OVA sensitized mice and saline sensitized controls (data not shown). This demonstrates that EC sensitization per se with OVA did not alter airway dynamics or enhance sensitivity to Mch. Fig. 7 shows that after a single exposure to inhaled OVA, OVA sensitized mice were more responsive to intravenous Mch than saline sensitized controls. Reduction of $\mathrm{C}_{\mathrm{dyn}}$ to $50 \%$ of baseline was achieved with a 10 -fold lower dose of Mch in OVA sensitized mice compared with saline sensitized controls (Fig. $7 \mathrm{~A}$, $P<0.05) . \mathrm{G}_{\mathrm{L}}$ was decreased in EC OVA sensitized mice compared with controls at all doses of Mch. However, the differences were not significant (Fig. $7 B$ ). These results suggest that antigen sensitization via the EC route leads to increased cho- linergic airway responsiveness after a single exposure to antigen by inhalation.

\section{Discussion}

This study demonstrates that EC application of a protein antigen in mice elicits a systemic immune response, local skin inflammation predominantly of Th2 type, and increased responsiveness to Mch after exposure to protein antigen.

EC sensitization, but not IP immunization, to OVA elicited a significant elevation of total serum IgE levels (Fig. 2). Moreover, there was a significantly more pronounced IgE and IgG1 antibody response and a lesser pronounced $\mathrm{IgG} 2 \mathrm{a}$ antibody response to OVA in EC sensitized mice compared with IP sensitized mice (Fig. 2, $B-D$ ). These results suggest that EC sensitization may be more prone to elicit a Th2 response.

More importantly, EC exposure to OVA elicited a local cutaneous inflammatory response. This response was characterized by thickening and inflammation in the dermis and epidermis and by infiltration of the dermal layer with neutrophils, eosinophils, mast cells, and mononuclear cells (Table II) that included $\mathrm{CD}^{+}$and $\mathrm{CD}^{+}$lymphocytes (Fig. 4). In addition, there was increased expression of the adhesion molecules ICAM-1 and VCAM-1. Skin lesions of patients with AD show a predominant infiltrate of $\mathrm{CD}^{+}, \mathrm{CD}^{+}$, and $\mathrm{CD} 45 \mathrm{RO}^{+}$cells 
A)

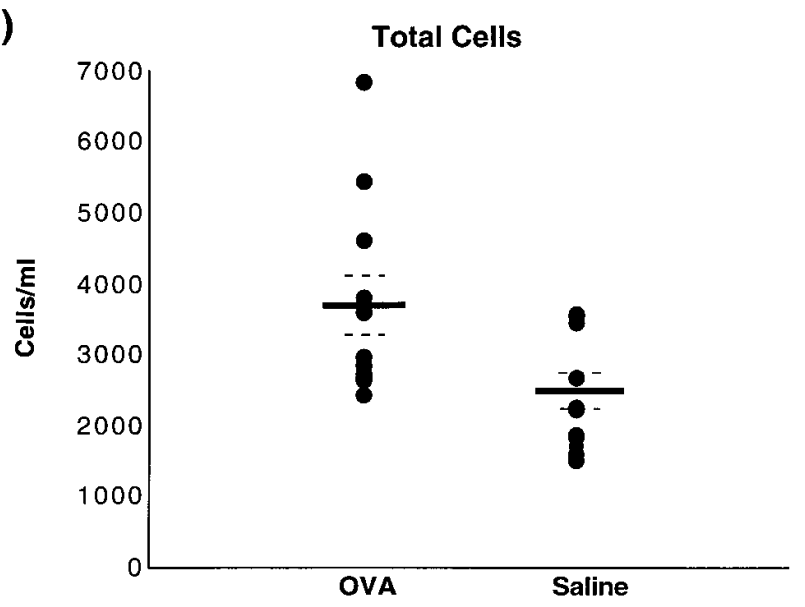

B)

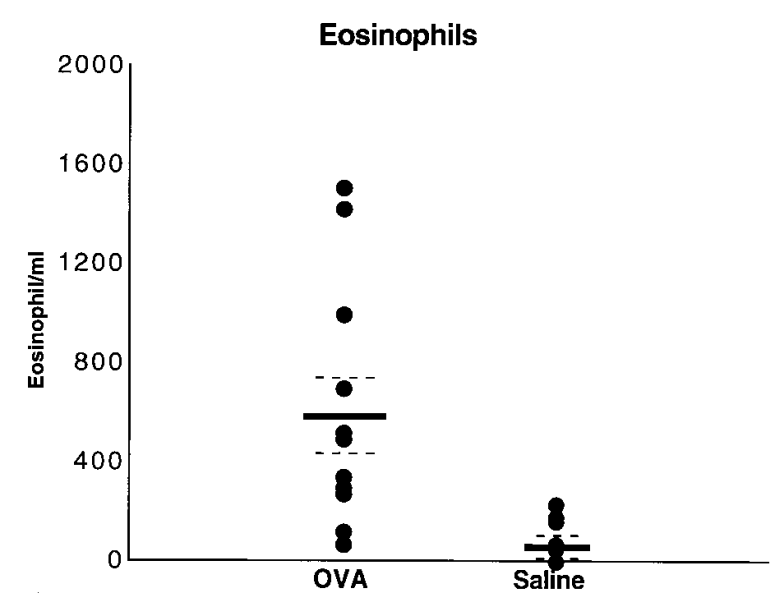

Figure 6. Total cells $(A)$ and eosinophils $(B)$ in BAL fluid from OVA and saline sensitized mice. BAL fluid was collected $24 \mathrm{~h}$ after a single exposure of inhaled $1 \%$ OVA via a nebulizer for $20 \mathrm{~min}$. Each group consisted of 10 mice. The solid bars and dashed lines represent the mean \pm SE. $P<0.01$ for eosinophil, $P<0.05$ for total cells.

with evidence of cellular activation as assessed by increased expression of MHC class II antigens (1) and expression of the adhesion molecules E-selectin, VCAM-1, and ICAM-1 (5). Evidence of eosinophil infiltration, with detection of eosinophil-derived major basic protein in the dermal layer by immunofluorescence, has been well documented in $\operatorname{AD}(6,24)$. Thus, the inflammatory lesion in the skin of mice EC sensitized with protein antigen shares several features with the skin lesions in AD.

Examination of cytokines in skin revealed that sensitization with OVA induced mRNA for the Th2 cytokines IL-4 and IL-5. IL-4 is the major cytokine that induces IgE synthesis in murine B cells (25). IL-5 is necessary for eosinophil development (26). The presence of eosinophils in EC sensitized skin together with the induction of a systemic IgE antibody response are consistent with induction of Th2 cytokines. In addition, there was evidence for increased IFN- $\gamma$, but not IL-2, mRNA in EC sensitized skin. In AD, acute skin lesions exhibit increased IL-4 and IL-5 mRNA and protein (27), whereas chronic lesions contain, in addition, increased levels of IFN- $\gamma$ mRNA and protein(28) suggesting a switch from an initial Th2 response to a mixed Th1 plus Th2 response. A switch in time from a Th2 to a mixed Th1 plus Th2 response is also observed when patch tests with house dust mite allergen are performed in patients with AD (28). Initially, IL-4 predominates over IFN- $\gamma$ at the site of antigen application, but later the situation is reversed and IFN- $\gamma$ predominates over IL-4 (3). Thus, the cytokine profile in the skin of mice EC sensitized with protein antigen is also similar to that of chronic lesions in AD.

Several mechanisms may underlie the induction of Th2 cytokines in response to EC sensitization with antigen. Induction of Th 2 cells requires the presence of IL- 4 early in T cell activation (29). The skin is enriched in mast cells which readily secrete IL-4 upon ligation of their IgE receptors. It has been reported that costimulation of T cells via ligation of CD28 by CD86 favors development of Th2 cells (30). CD86 is basally

A)

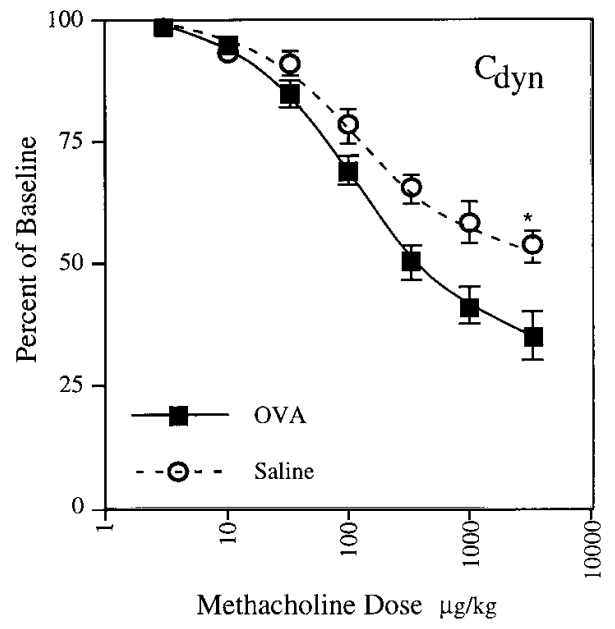

B)

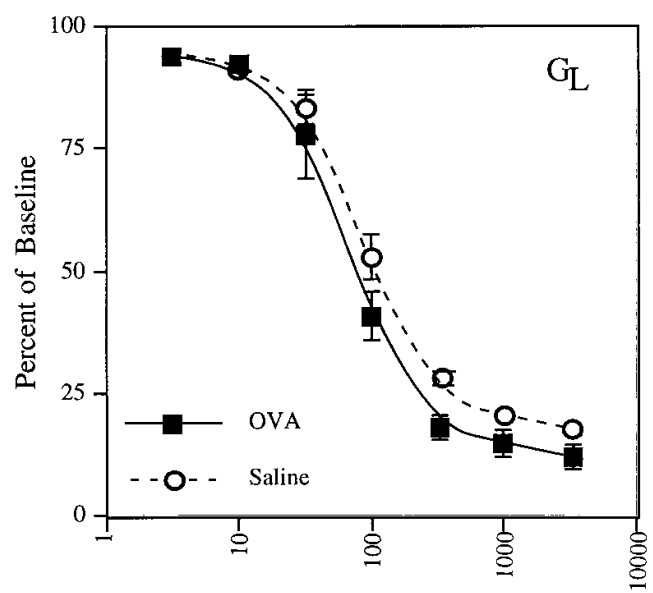

Figure 7. $\mathrm{G}_{\mathrm{L}}(A)$ and $\mathrm{C}_{\mathrm{dyn}}(B)$ in OVA and saline-EC sensitized mice after OVA inhalation. $\mathrm{C}_{\mathrm{dyn}}$ and $\mathrm{G}_{\mathrm{L}}$ are plotted as a percentage of the baseline. Airway measurements were taken $24 \mathrm{~h}$ after one dose of nebulized $1 \%$ OVA $(* P<0.05$, ANOVA). Data are mean \pm SE ( $n=6 /$ group $)$. 
expressed on Langerhans cells, the major antigen-presenting cells in the skin (31). Ligation of CD40L by CD40 has been reported to favor Th2 cell development (32). CD40 is readily expressed on activated keratinocytes, such as those treated with IFN- $\gamma$ (33), and we found that CD40L is expressed on cells that infiltrate the skin lesion at the site of EC sensitization (manuscript in preparation). Finally repeated stimulation with antigen, as in our sensitization protocol, favors the development of Th2 cells, possibly because Th2 cells are more resistant to apoptosis induced by FasL expressed by activated $\mathrm{T}$ cells (34). This resistance may be related to the higher expression in Th2 cells of the Fas-associated phosphatase FAP(34).

The expression of IFN- $\gamma$ together with the Th2 cytokines IL-4 and IL-5 in our model of EC antigen sensitization and in AD may possibly be explained by the observation that Th2 cells induce IL-12 production by dendritic cells via a CD40LCD40-dependent pathway (35). IL-12 induces Th0 cells to differentiate into IFN- $\gamma$-secreting Th1 cells $(36,37)$. Amplification of IFN- $\gamma$ secretion occurs because IFN- $\gamma$ acts in concert with IL-12 to induce the Th2 cells to secrete IFN- $\gamma$ along with IL-4 and IL-5 $(35,38)$. An alternative explanation is that IFN- $\gamma$ is from another cell type, i.e., macrophages. The role of IFN- $\gamma$ can be postulated as a proinflammatory cytokine as the lesions become chronic.

Several studies have suggested a role for cutaneous exposure to aeroallergens in the pathogenesis of $\mathrm{AD}$. It has been shown that contact with specific aeroallergens can cause flares of AD (39). Application of aeroallergens which elicit an $\mathrm{IgE}$ response in AD results in the appearance of an eczematous reaction $(11,40)$. Avoidance of the same aeroallergens results in improvement of the dermatitis (13). These observations, together with the similarity of the cellular infiltrate and cytokine profile in the skin of AD patients and the skin of EC sensitized mice, suggest that EC sensitization may be a potential model of AD.

Two recent models of murine allergic dermatitis have been proposed. In one model, systemic dermatitis, eosinophilic infiltration in the skin, and elevated serum IgE developed in $\mathrm{BALB} / \mathrm{c}$ mice after peritoneal injection with Schistosoma japonicum glutathione-S-transferase (41). The second model consists of the inbred strain of $\mathrm{NC} / \mathrm{Nga}$ mice, which when reared under conventional non-pathogen-free conditions develop chronic relapsing inflammation of the skin with infiltration of $\mathrm{CD}^{+}$cells and elevated serum IgE levels (42). In neither of these models has the local cytokine profile or the changes in airway reactivity been examined.

A most interesting feature of EC sensitization with protein antigen is that it led to antigen-specific airway sensitivity. A single exposure of EC sensitized mice to aerosolized OVA was followed by accumulation of eosinophils in the BAL fluid. More importantly, it resulted in airway hyperresponsiveness to a Mch challenge administered $24 \mathrm{~h}$ later as evidenced by a significant 10-fold reduction in the dose of Mch required to achieve a $50 \%$ reduction in baseline pulmonary $\mathrm{C}_{\mathrm{dyn}}$. Our results expand a previous observation that mice sensitized by repeated painting of antigen on the skin and exposure to inhaled antigen exhibit increased contractility of tracheal smooth segments in response to electrical field stimulation in vitro (15). Our study found that airways have increased cholinergic response in live animals and local allergic dermatitis.

Patients with AD display bronchial hyperresponsiveness to histamine regardless of clinical evidence of asthma (43). More- over, in patients with both $\mathrm{AD}$ and asthma, $\mathrm{AD}$ develops well before asthma becomes clinically evident. It is possible that cutaneous sensitization to aerosolized allergens such as house dust mite induces airway sensitivity to these allergens in patients with AD. Recurrent exposure to these allergens by inhalation may exacerbate the bronchial hyperresponsiveness and underlie the high risk for the development of allergic asthma in these patients.

The mechanism(s) responsible for airway sensitization after EC exposure to protein antigen remain to be investigated. IgE, T cells, the T cell-derived cytokines IL-4 and IL-5 and chemokines have been implicated in the development of airway sensitivity after IP immunization followed by repeated exposure to inhaled antigen (44-46). The fact that airway sensitivity develops in IgE-deficient as well as B cell-deficient mice suggests that immunoglobulins, including $\operatorname{IgE}$, may not be necessary for airway sensitization to antigen $(47,48)$. However, passively transferred IgE has been shown to induce airway sensitization (49). Additionally, passive transferred immune serum either locally or systematically from patients with AD can lead to eczematous lesions in patch test with aeroallergens (50). Taken together these data suggest that both $\mathrm{T}$ cells and IgE may independently contribute to the development of antigen-specific airway responsiveness. Currently, we are examining the role of $\mathrm{T}$ and $\mathrm{B}$ cells, immunoglobulins, and cytokines in our model.

In summary, we have investigated a mouse model of EC sensitization with protein antigen that leads to local allergic dermatitis and to antigen-specific airway responsiveness. There is reason to believe that this model may be related to AD and thus may be used to investigate pathophysiologic mechanisms and test therapeutic interventions in AD. In addition, our model may shed light on the relationship between AD and allergic asthma.

\section{Acknowledgments}

We would like to thank Hans Oettgen for his critical reading of the manuscript. We also thank David Zurakowski for his help with the statistical analysis.

J.M. Spergel was supported by Glaxo Wellcome Allergy Training Award and Child Health Research Center grant NICHD P30HD27805. This work was also supported by National Institutes of Health (NIH) grants DK47677 and DK43551 to A.K. Bhan and NIH grants AI 31541, AI 31136T, and 32AI07512 to R.S. Geha. R.S. Geha also acknowledges the support of Baxter, Olsten, and Alpha Therapeutics Corporations.

\section{References}

1. Leung, D.Y.M. 1995. Atopic dermatitis: the skin as a window into the pathogenesis of chronic allergic disease. J. Allergy Clin. Immunol. 96:312-319.

2. Leung, D.Y.M. 1992. Immunopathology of atopic dermatitis. Springer Semin. Immunopathol. 13:427-440.

3. Thepen, T., E.G. Langeveld-Wildschut, I.C. Bihari, D.F. van Wichen, F.C. van Reijsen, G.C. Mudde, and C. Bruijnezeel-Koomen. 1996. Biphasic response against aeroallergen in atopic dermatitis showing a switch from an initial Th2 response to a Th1 response in situ: an immunocytochemical study. J. Allergy Clin. Immunol. 97:828-837.

4. Jung, K., F. Linse, R. Heller, C. Moths, R. Goebel, and C. Neumann. 1996. Adhesion molecules in atopic dermatitis: VCAM-1 and ICAM-1 expression is increased in healthy-appearing skin. Allergy. 51:452-460.

5. Wakita, H., T. Sakamoto, Y. Tokura, and M. Takigawa. 1994. E-selectin and vascular cell adhesion molecule- 1 as critical adhesion molecules for infiltration of T lymphocytes and eosinophils in atopic dermatitis. J. Cutaneous Pathol. 21:33-39. 
6. Leiferman, K.M. 1994. Eosinophils in atopic dermatitis. J. Allergy Clin. Immunol. 94:1310-1317.

7. Platts-Mills, T.A.E., M.D. Chapman, S. Michell, P.W. Heymann, and B. Deull. 1991. Role of inhalant allergens in atopic eczema. In Handbook of Allergens in Atopic Eczema. T. Ruzicka, J. Ring, and B. Prybila, editors. SpringerVerlag, Heidelberg. 192-203.

8. Jones, S.M., and H.A. Sampson. 1993. The role of allergens in atopic dermatitis. Clin. Rev. Allergy. 11:471-490.

9. Tupker, R.A., J.G. Monchy, P.J. Coenraads, A. Homan, and J.B. van der Meer. 1996. Induction of atopic dermatitis by inhalation of house dust mite. $J$. Allergy Clin. Immunol. 97:1064-1070.

10. Hoffman, D.R., F.Y. Yamamoto, B. Geller, and Z. Haddad. 1975. Specific IgE antibodies in atopic eczema. J. Allergy Clin. Immunol. 55:256-267.

11. Mitchell, E.B., J. Crow, M.D. Chapman, S.S. Jouhal, F.M. Pope, and T.A.E. Platts-Mill. 1982. Basophils in allergen-induced patch test sites in atopic dermatitis. Lancet. 1:127-130.

12. Roberts, D.L. 1984. House dust mite avoidance and atopic dermatitis. Br. J. Dermatol. 110:735-736.

13. Tan, B., D. Weald, I. Strickland, and P. Friedmann. 1996. Double-blind controlled trial of effect of housedust-mite allergen avoidance on atopic dermatitis. Lancet. 347:15-18.

14. Sager, N., A. Feldman, G. Schilling, P. Kreitsch, and C. Neumann. 1992. House dust mite-specific $\mathrm{T}$ cells in the skin of subjects with atopic dermatitis: frequency and lymphokine profile in the allergen patch test. J. Allergy Clin. Immunol. 89:801-810.

15. Saloga, J., H. Renz, G.L. Larsen, and E.W. Gelfand. 1994. Increased airways responsiveness in mice depends on local challenge with antigen. Am. J. Respir. Crit. Care Med. 149:65-70.

16. Wang, L.-F., J.-Y. Lin, K.-H. Hsieh, and R.-H. Lin. 1996. Epicutaneous exposure of protein antigen induces a predominant $\mathrm{TH} 2$-like response with high IgE production in mice. J. Immunol. 156:4079-4082.

17. Renz, H., H.R. Smith, J.E. Henson, B.S. Ray, C.G. Irvin, and E.W. Gelfand. 1992. Aerosolized antigen exposure without adjuvant causes increased $\mathrm{IgE}$ production and increased airway responsiveness in the mouse. J. Allergy Clin. Immunol. 89:1127-1138.

18. Mombaerts, P., E. Mizoguchi, M. Grusby, L.H. Glimcher, A.K. Bhan, and S. Tonegawa. 1993. Spontaneous development of inflammatory bowel disease in T cell receptor mutant mice. Cell. 75:275-282.

19. Shire, D., and the Editorial staff of European Cytokine Network. 1993. An invitation to an open exchange of reagents and information useful for the measurements of cytokine mRNA levels by PCR. Eur. Cytokine Network. 4: $161-162$.

20. Bouaboula, M., M.P. Legous, B. Pessegue, B. Delpech, X. Dumont, M. Piechaczyk, P. Casellas, and D. Shire. 1992. Standardization of mRNA titration using a polymerase chain reaction method involving co-amplification with a multispecific internal control. J. Biol. Chem. 267:21830-21838.

21. Martin, T.R., N. Gerard, S. Galli, and J.M. Drazen. 1988. Pulmonary responses to bronchoconstrictor agonists in the mouse. J. Appl. Physiol. 64:23182323.

22. Kroeker, J.P. 1977. Weiner analysis of nonlinear systems using PoissonCharlier cross-correlation. Biol. Cybern. 27:221-227.

23. Bousquet, J., P. Charex, J. Lacoste, G. Barneon, N. Ghavanian, I. Enander, P. Venge, S. Ahlstedt, J. Simon-Lafontaine, and P. Godard. 1990. Eosinophilic inflammation in asthma. N. Engl. J. Med. 323:1033-1039.

24. Leiferman, K.M., S.J. Ackerman, H.A. Sampson, H.S. Haugen, P.Y. Venencie, and G.J. Gleich. 1985. Dermal deposition of eosinophil-granule major basic protein in atopic dermatitis: comparison with onchocerciasis. N. Engl. J. Med. 313:282-285.

25. Vercelli, D., and R.S. Geha. 1992. Regulation of isotype switching. Curr. Opin. Immunol. 4:794-797.

26. Sanderson, C.J. 1992. Interleukin-5, eosinophils, and disease. Blood. 79: 3101-3109.

27. Hamid, Q., M. Boguniewicz, and D.Y.M. Leung. 1994. Differential in situ cytokine gene expression in acute versus chronic atopic dermatitis. J. Clin. Invest. 94:870-876.

28. Werfel, T., A. Morita, M. Grewe, H. Renz, U. Wahn, K. Krutmann, and A. Kapp. 1996. Allergen specificity of skin-infiltrating T cells is not restricted to type-2 cytokine pattern in chronic skin lesions of atopic dermatitis. J. Invest. Dermatol. 107:871-876.

29. Coffman, R., and T. von der Weld. 1997. Multiple pathways for the initiation of T helper 2 (Th2) responses. J. Exp. Med. 185:373-375.
30. Ranger, A.M., M.P. Das, V.K. Kuchroo, and L.H. Glimcher. 1996. B7-2 (CD86) is essential for the development of IL-4 producing cells. Int. Immunol. 8:1549-1560.

31. Kawamura, T., and M. Furue. 1995. Comparative analysis of B7-1 and B7-2 expression in Langerhans cells: differential regulation by $\mathrm{T}$ helper type I and T helper type 2 cytokines. Eur. J. Immunol. 25:1913-1917.

32. Macaulay, A.E., R.H. DeKruyff, C.C. Goodnow, and D.T. Umetsu. 1997. Antigen-specific B cells preferentially induce CD4+ T cells to produce IL-4. J. Immunol. 158:4171-4179.

33. Denfeld, R.W., D. Hollenbaugh, A. Fehrenbach, J.M. Weiss, A. van Leoprechting, B. Mai, U. Voith, E. Schopf, A. Aruffo, and J.C. Simon. 1996. CD40 is functionally expressed on human keratinocytes. Eur. J. Immunol. 26:2329 2334.

34. Zhang, X., T. Brunner, L. Carter, R.W. Dutton, P. Rogers, L. Bradley, T. Sato, J.C. Reed, D. Green, and S.L. Swain. 1997. Unequal death in T helpe cells (Th) 1 and Th2 effectors: Th1, but not Th2, effectors undergo rapid Fas/ FasL-mediated apoptosis. J. Exp. Med. 185:1837-1849.

35. Vezzio, N., S. Sarfati, L.-P. Yang, C.E. Demeure, and G. Delespesse. 1996. Human Th2-like cell clones induce IL-12 production by dendritic cells and may express several cytokine profiles. Int. Immunol. 8:1963-1970.

36. Hsieh, C.-S., S.E. Macatonia, C.S. Tripp, S.F. Wolf, A. O'Garra, and K.M. Murphy. 1993. Development of TH1 CD4+ T cells through IL-12 produced by Listeria-induced macrophages. Science. 260:547-549.

37. Seder, R.A., R. Gazzinelli, A. Sher, and W.E. Paul. 1993. Interleukin-12 acts directly on $\mathrm{CD} 4+\mathrm{T}$ cells to enhance priming for interferon-gamma production and diminishes interleukin 4 inhibition of such priming. Proc. Natl. Acad. Sci. USA. 90:10188-10192.

38. Hu-Li, J., H. Huang, J. Ryan, and W.E. Paul. 1997. In differentiated CD4+ T cells, interleukin 4 production is cytokine-autonomous, whereas interferon $\gamma$ production is cytokine-dependent. Proc. Natl. Acad. Sci. USA. 94:31893194.

39. Clark, R.A.F., and A.D. Adinoff. 1989. Aeroallergen contact can exacerbate atopic dermatitis: patch tests as a diagnostic tool. J. Am. Acad. Dermatol. 21:863-869.

40. Bruijnzeel-Koomen, C., D. van Wichen, C. Spry, P. Venge, and P. Bruijnzeel. 1988. Active participation of eosinophils in patch test reactions to inhalant allergens in patients with atopic dermatitis. Br. J. Dermatol. 118:229-238.

41. Hsu, C.-H., K.-Y. Chua, S.-K. Huang, I.-P. Chiang, and K.-H. Hsieh. 1996. Glutathione-S-transferase induces murine dermatitis that resembles human atopic dermatitis. Clin. Exp. Allergy. 26:1329-1337.

42. Matsuda, H., N. Watanabe, G.P. Geba, J. Speri, M. Tsudzuki, J. Hiroi, M. Matsumoto, H. Ushio, S. Saito, P.W. Askenase, and C. Ra. 1997. Development of atopic dermatitis-like skin lesion with IgE hyperproduction in NC/Nga mice. Int. Immunol. 9:461-466.

43. Salob, S.P., A. Laverty, and D.J. Atherton. 1993. Bronchial hyperresponsiveness in children with atopic dermatitis. Pediatrics. 91:13-16.

44. MacLean, J.A., R. Ownby, and A.D. Luster. 1996. T cell-dependent regulation of eotaxin in antigen-induced pulmonary eosinophilia. J. Exp. Med. 184 1461-1469.

45. Drazen, J.M., J.P. Arm, and K.F. Austen. 1996. Sorting out the cytokines of asthma. J. Exp. Med. 183:1-5.

46. Gonzalo, J-A., C.M. Lloyd, L. Kremer, E. Finger, C. Martinez-A, M.H. Siegelman, M. Cybulisky, and J.C. Gutierrez-Ramos. 1996. Eosinophil recruitment to the lung in a murine model of allergic inflammation. The role of T cells, chemokines and adhesion receptors. J. Clin. Invest. 98:2332-2345.

47. Mehlhop, P.D., M. van der Rijn, A.B. Goldberg, J.P. Brewer, V.P. Kurup, T.R. Martin, and H.C. Oettgen. 1997. Allergen-induced bronchial hyperreactivity and eosinophilic inflammation occur in the absence of $\operatorname{IgE}$ in a mouse model of asthma. Proc. Natl. Acad. Sci. USA. 94:1344-1349.

48. Korsgren, M., J.S. Erjeflat, O. Korsgren, F. Sundler, and C.G. Persson. 1997. Allergic eosinophil-rich inflammation develops in lungs and airways of B cell-deficient mice. J. Exp. Med. 185:885-892.

49. Hamelmann, E., A.T. Vella, A. Oshiba, J.W. Kappler, P. Marrack, and E.W. Gelfand. 1997. Allergic airway sensitization induces T cell activation but not airway hyperresponsiveness in B cell-deficient mice. Proc. Natl. Acad. Sci. USA. 94:1350-1355.

50. Mitchell, E.B., J. Crow, S. Rowntree, A.D.B. Webster, and T.A.E. Platts-Mills. 1984. Cutaneous basophil hypersensitivity to inhalant allergen in atopic dermatitis patients: elicitation of delayed responses containing basophils following local transfer of immune serum but not IgE antibody. J. Invest. Dermatol. 83:290-295. 